\title{
Engineering Education in the 21st Century: Creativity, Collaboration, Invention
}

\author{
Joan Marie Kelly
}

\begin{abstract}
Engineers need to be the artists of the future, creatively solving problems of complex systems, environments, and cultures in a globally connected world. The nature of these problems demands that the engineer make connections between what may appear divergent and polarized. Why do artists study methods of creativity yet engineers do not? What possibilities open up when classrooms around the world teach collaboratively? In a new engineering program at Nanyang Technological University, in Singapore, engineers are studying Western figure drawing while also learning collaboratively with classrooms from America. This partnering invites the unexpected by mixing up the various contexts of the learners and facilitating insights. The Nanyang engineering program is giving students the ability to use traditional figure drawing while also learning collaboratively with classrooms from America.
\end{abstract}

Index Terms-Collaboration, creativity, drawing, engineering education, innovation.

\section{INTRODUCTION}

This research discusses the benefits for engineering students of studying drawing. Part one will discuss how the study of drawing can be a source of creativity and invention, a developmental process that generates and records ideas. Part two describes processes and outcomes of a collaborative, multicultural learning model between engineering students from Singapore and liberal arts students from the United States.

With more and more urgency, engineering education programs are being asked by practitioners in the field to adapt to the ever-changing, grand challenges of our future. These challenges are conditioned by global networks of interconnected systems. Among the voices calling for rethinking the entire paradigm of engineering education, are Dr. Charles Vest, President of the National Academy of Engineering. In a series of visionary talks, Vest elaborates on the need for engineering education to integrate with the social sciences and for engineers to think critically across academic disciplines, ethnicities, cultural differences, and political boundaries. "Engineers of today and tomorrow must be prepared to conceive and direct projects of enormous complexity that require a highly integrative view of engineering systems," Vest states. And, "My primary advice regarding engineering education is that making universities and engineering schools exciting, creative, adventurous, rigorous, demanding, and empowering milieus is more important than specifying curricular details." As part

Manuscript received October 28, 2012; revised January 13, 2013.

Joan Marie Kelly is with Nanyang Technological University, Singapore (e-mail:jmkelly@ntu.edu.sg). of his call for innovation, Vest uses the term "Brain Integration" to signify researchers in different locations who link together to integrate their thinking [1].

In a similar vein, Harold P. Sjursen from Polytechnic University in Brooklyn, New York, argues:

"A simple curricular solution cannot address adequately these profound challenges. Rather, engineering and humanities educators need to form discursive alliances, based on mutual respect, that will enrich understanding and create the basis for meaningful deliberation. . . . curriculum change . . . needs to occur within an environment that nurtures fundamental discourse between engineers, technologists, scientists, and the full range of humanists and social commentators [2]."

Sjursen summarizes, "Engineers must be humanists in order to exercise their vocation responsibly [3]."

For nations facing problems like global warming, housing shortages, mass transportation needs, and energy consumption and sustainability, public engineering projects are part of the solution. Yet, to the extent that these problems arise out of lifestyle priorities and belief systems, wide-ranging discourse is also needed as a part of the solution. As such, engineering and the humanities are connected - even entwined.

\section{WHAT IS DRAWING?}

An ancient Greek legend describes the origins of drawing. The young daughter of a Corinthian potter was in love with a shepherd forced to go off to war. She didn't want the vision of his face to fade from her memory, so while he was sleeping one night, she drew the contours of his profile on the wall behind him as the lamp cast the shadow from his face. Later, her father pressed clay into the shape and created a relief, inventing the practice of modeling portraits from clay. There are a considerable number of interpretations analyzing the myth philosophically and historically. Deanna Petherbridge sees the story as a developmental process, with the myth as "Origination, it also represents completion, supporting the notion of drawing as a continuum stretched between beginning and end, ondos and telos. The father fills the daughter's initiatory outline with clay just as an inventive sketch can generate a developmental chain process, which might require an act of closure in another medium [4]."

In order for development to occur, a sketch needs to have a sense of the incomplete. Here, the term development means a process of transformation, from one stage to another to generate ideas, problem-solving, the clarification of intention, and/or evolution of the original thought. In 
addition, the sketch is "open" meaning the maker can intercede at anytime working back into the sketch. It should be noted that whereas digitally tools made drawings have a tendency to look finished and final from the beginning. Regardless of the innovations of technology, the drawing made with the hand holds a simplicity, accessibility, and autographic uniqueness.

\section{SKetching TO INVENT}

For engineering students, the open-ended process of sketching can be experienced and practiced in two ways: through the use of reference materials, and with raw materials. Gathering references, textual and visual, is what academia calls "field work." To begin, engineering students may be giving specific topics or events to respond to. In the case studies for the research presented here, students from Nanyang Technological University taught by Asst/Prof. Joan Marie Kelly in Singapore, were given the topic "Home." Many worked directly from their own experiences to develop their idea and then moved to references to develop their idea pictorially. References included photography, sketches from nature, other artists' work, imagination, and memory.

The second process uses raw materials to generate ideas through action and imagination. Happy accidents and unexpected results take place when raw materials are juxtaposed with each other; there is an intuitive aspect as well. The following accounts, by two Nobel Prize physicists, exemplify this. Andre Geim and Konstantin Novoselov are describing the atmosphere of their Friday night experiments, which induced their discovery of the layering of lead. Geim says,

“... late evening or Friday night experiments [are] where you try something very elementary and try to go into one or another direction, and, ninety nine times out of hundred, you do not succeed, but, sometimes there are very simple experiments and very simple discoveries to be made using what is at hand. [5]."

Novoselov says,

"...that's exactly the spirit of this Friday evening experiment. You are not allowed to use any complicated machinery or anything. You just do something on your knees with your bare hands and if it works, it works. [6]."

Likewise, with the sketch, the place and time for it must be informal. There must be a sense that failure is not only acceptable, but a part of the process of discovery. As Novoselov notes, rudimentary tools are a part of the process.

Drawing from observation-perceptual drawing-is fundamentally instructive to engineering education. Perceptual drawing is a means for re-learning the world. By studying the physical world, students enhance their observational skills and their relationship to their environment. Spending time with a subject fosters empathy, and reveals the complexities and histories of place. Perceptual drawing peels away the idea of what one sees, and trains the eye to begin to see what is in front of them. This is what artists mean when they refer to being taught to "see" rather than just to "look." There are no lines in our world, only color, shapes, edges, textures, and tones-yet we use lines to translate the three-dimensional world to the two- dimensional. The student studies the tangible world and in the process expresses intangible thoughts, and emotions. Richard Hare notes that,

“. . . sketching and drawing are a means of extending and simultaneously transforming our understanding rather than simply a means to let others know what we think or even ways of revealing to ourselves what we think [7]."

For the "Home" assignment, first-year engineering student Xiang Qiuyu, from mainland China, produced the graphite drawing titled "My Parents." Qiuyu did not have any drawing experience before she entered the engineering program at Nanyang. She reinterprets the work of artist Edward Hopper via an issue that is of importance to her personally. She puts the personal issue into the context of a social condition facing China. Her process entails selecting, rejecting, modifying, and re-interpreting Hopper's visual elements, and using imagery from memories of her parent's and her bedroom. Qiuyu debunks the myth that the artist's talent is a mysterious gift from above that he or she is not in control of. As artist Chuck Close says, "Inspiration is for amateurs; the rest of us just show up and get to work [8]."

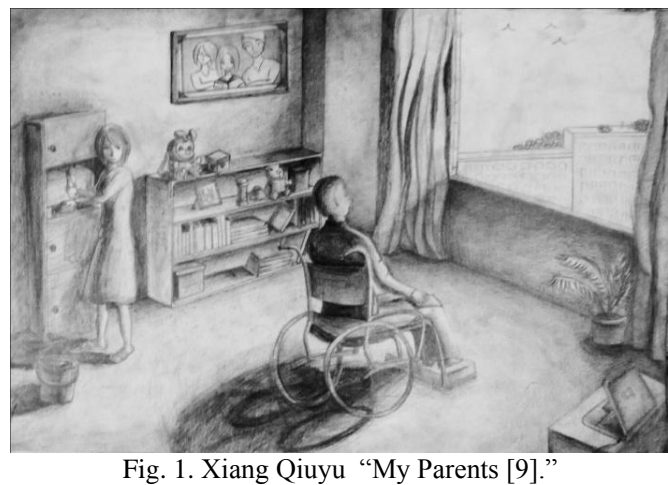

In Fig. 1, we will look now at the creative methodology Quiyu uses to build her ideas and imagery. She writes,

“...this picture is also a real portrait of most Chinese families now. China implemented one child policy in $1980 \ldots$. when most of 1980s generation grew up and left home, these parents easily lost their balance of life especially when they face retirement and sickness. Windows are good metaphors of people's loneliness and emptiness. In this drawing, the father looks outside the window and seems to be imagining his daughter's life overseas. But he cannot see anything outside other than emptiness. Sunlight shoots into the room and creates a mood of missing. The mother is cleaning the bookshelf. Even though her daughter has not been home for a few years, she still keeps the habit of cleaning her daughter's books and toys .... It hints at the child's importance to this family. When the mother looks at the father, she feels wordless because she is quite worried for the father's health[10]."

Through this drawing assignment Quiyu, as an engineering student, devised investigations in order to magnify social science issues. The ability to perceive the scope of a social science issue is needed to develop technologies that have the potential to solve societal problems. Quiyu probes: family relationships in the manmade architectural space; the isolation, mobility, and 
immobility of the man in the wheel chair; issues of communication over distances; the pressures that China's one-child laws put on parents and children; and issues of aging. Drawing assignments could be geared to correspond to specific engineering problem-solving and surrounding social science questions. This is very different from the more conventional understanding of the use of the sketch: to brainstorm design ideas for specific technologies or forms. The use of drawing as a brainstorming and realization process has equal importance in both strategies; both can be used by the engineering student.

In his book, The Art of Scientific Investigation, W. I. B. Beveridge gives examples of the role of imagination:

"In meditating thus, many people find that visualizing the thoughts, forming mental images, stimulates the imagination. It is said that Clerk Maxwell developed the habit of making a mental picture of every problem. Paul Ehrlich was another great advocate of making pictorial representations of ideas as one can see from his illustrations of his side-chain theory. Pictorial analogy can play an important part in scientific thinking [11]."

Beveridge then supplies an excerpt from German chemist Friedrich August Kekule chemical textbook as to how Kekule hit upon the conception of the benzene ring:

"But it did not go well; my spirit was with other things. I . . . sank into a half sleep. The atoms flitted before my eyes. ... All in a movement wriggling and turning like snakes. ... One of the snakes seized its own tail and the image whirled scornfully before my eyes. As though from a flash of lightening I awoke; I occupied the rest of the night in working out the consequences of the hypothesis. . . . Let us learn to dream, gentlemen [12]."

The developmental process of the sketch builds a virtual space for the engineer's imagination to explore. Moreover, the artifact that remains - marks on paper- traces the metamorphosis of visualizations and thoughts of the maker.

\section{Teaching Philosophy}

The teaching philosophy with which drawing is taught to the engineering student must also reflect the teaching philosophy of the fine art classroom. Charles Vest states, "Where imaginations play, learning happens."

The classroom is fashioned as a drawing/painting studio that operates as a physically active, interactive, communitylearning exchange. By working in proximity to each other, the students bear witness to one another's drawing and thinking processes.

In the online classroom, diverse tools are needed in order for teaching to be most effective and stimulating. Qualities such as scale, texture, and transparency of the medium are lost when viewed on the monitor. Thus, the online classroom must leverage its own virtues - of communication over distances and of the engagement and exchanges among students from diverse cultures. While witnessing each other drawing and problem- solving in the classroom, online chats, discussions, and critiques take place.

The drawing studio classroom engages inductive, deductive, and kinesthetic ways of learning. In Richard M.
Feldeer's paper, "Learning and Teaching Styles in Engineering Education," he argues, "Active learners do not learn much in situations that require them to be passive and reflective learners do not learn much in situations that provide no opportunity to think about the information being presented [13]." Among the different methods employed are lectures, visual presentations, practice making/drawing, and critiques of the work produced. Sketching at the museum, or on location, can bring drawing into the lifestyle of the student so that she or he grows more aware of the daily environment-important for innovation.

When teaching, Prof. Kelly, makes references to her students' communities. This prompts the students to investigate their communities and validate them at the same time. In places that are rooted in a colonial past, where the West is looked to for validation, this can be significant. For creativity and innovation to play out, confidence is needed, because risks must be taken.

The engineering students are treated as artists, recognized in light of the teacher-student relationship, in which each artist is at a different point of his or her learning process. To break down expectations and pre-conceived ideas of success or failure, references are not made to right or wrong. Thus, the engineering students take risks in the beginning. Student work is viewed as having its own integrity, empowering students to have the confidence to find their own solutions to their drawn ideas.

\section{Collaborating Classrooms OVER Distances}

The two beginning perceptual drawing courses discussed here are from Nanyang Technological University in Singapore (taught by Joan Marie Kelly) and the University of New Hampshire (taught by Suzanne Schireson). Environmentally and culturally, the work of the two student bodies reflects their differences. Singapore's population is upwards of 5 million, its land-mass is 695 sq. km., or 268 sq. mi. It is a city-state with three main ethnic groups: Chinese, Malay, and Indian. Living year-round in the tropical heat, people spend their free time in air-conditioned shopping malls. In the last forty years, Singapore has gone from having ethnic groups who live in communities formed around a temple or a market, to multitudes living under a skyline of high-rises that form a repetitious geometry. Singaporean students are especially anxious to discover a unique identity for themselves. Drawing offers an exciting opportunity to produce an original piece that can be identified as autographic.

In contrast, the University of New Hampshire (UNH) students live in a state whose license plate reads, "Live Free or Die." The campus is situated among forests. Students are Caucasian and middle class.

The collaboration between the two classrooms began thus: Kelly in Singapore and Schireson in the U.S. gave their students the same assignment, with the same objective: to produce a formal drawing, and to reflect on their own society and lifestyle. Because the U.S. and Singapore students were partnered with one another to communicate and share as they went along, the assignments addressed connections between the two different cultural perspectives.

Both classrooms were given the concept "Home" The 
majority of the UNH drawings depicted natural spaces. None of them included the human figure. In one, lights shine from the windows of a home, evidence of people inside. The students live in single-family homes with driveways and land surrounding each house. In New Hampshire, this is a middle class setting, but in Singapore such housing is owned exclusively by the extremely wealthy.

The "Home" assignment raised many questions for the Singapore student as to how Singaporeans use and relate to the natural environment. The following drawing is an example of this discourse. Singapore Student \#3 titles the drawing: "American Dream: One House One Car One Person.”(see Fig. 2)

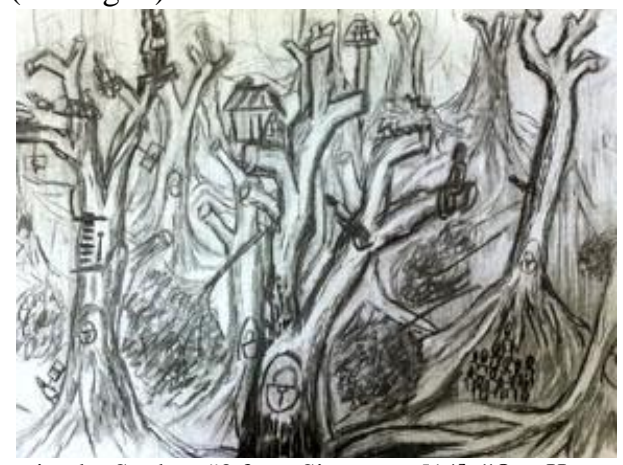

Fig. 2. Drawing by Student \#3 from Singapore [14], "One House, One Car, One Person"

Singapore Student \#3 writes about her responses to the drawing of Margaret, her partner in the U.S.:

"From Margaret's drawing: can tell how the average American can have a huge piece of land to themselves. In Asia: in Cities like Singapore, our high population density does not allow this to happen.

As I see my partner's drawing of how she had a lot of trees. I see it as a huge contrast to Singapore that have limited land area, where these same trees are chopped away for more spaces. Houses, cars, buildings etc replaced the nature.

Space in Singapore is restricted, and controlled. In New Hampshire, the logo is "live Free or Die", well in Asia, we cannot afford that. Everything that one does will be restricted by boundaries like rules. Also, another practical fact will be the division of people of how much CASH they have.

Indeed, Singapore is known as the garden city, however, the trees are planted on "empty slots" after land has being used for accommodations.

Trees in partner's drawing symbolize the "free spirit", the right to grow. Trees in my drawing symbolize sacrifice and boundaries, to grow you have to be shaped first. To have sustainable progress, what Asia needs will be the talents gone overseas returning back to their homeland [15]."

\section{CONCLUSIONS}

The study of drawing by engineering students fulfills some of the core of the recommendations of leaders in the field for more robust interaction between the humanities and engineering education. The examples in this paper are only a portion of the students' work, but they demonstrate critical thinking skills as well as the students' facility for making connections between seemingly disparate ideas via drawing methodologies.

One night, the two classes joined on Skype - an event that should have happened more often and probably from the beginning. The Singaporean class was very anxious to get to know the Americans. They described their drawing ideas and the types of materials and marks they used to express the intended emotive quality of the drawing. In contrast, the Americans gave simple, one-sentence answers to their ideas. For example, "I like baseball so I drew a baseball." Here is one of the feedback comments by a student from Singapore

Me and my partner could look at our pieces in a different way (for example, I wrote that my partner's Ramen and peanut butter, which kind of looks like Japan's rising sun flag,_gave me the impression that he might be a huge fan of Japanese culture. But my interpretation was really different from his intention of drawing). . . . Such an eye-opening session [16]."

In short, firsthand, direct experience with students of other cultures breaks down stereotypes and develops understand and empathy for others societal circumstances. The collaborative classroom broadened the learning outcomes from drawing to social science interests. Because the engineer must emphasize creativity and innovation, drawing practice presents an open methodology waiting to be utilized - in fact, crying to be utilized-by the engineering field. For meeting engineering's creative demands, the collaborative classroom is a model for future teaching

\section{REFERENCES}

[1] C. M. Vest. (Feb 23, 2010). Engineering, Innovations and the Challenges of the $21^{\text {st }}$ Century. Vanderbilt University. [Online]. Available: http://www.youtube.com/watch?v=1_cV1FmiUKw

[2] H. P. Sjursen, "The New Alliance between Engineering and Humanities Educators," Global J. of Engng. Educ., vol. 11, no. 2, pp. 135 .

[3] H. P. Sjursen, "The New Alliance between Engineering and Humanities Educators," Global J. of Engng. Educ., vol. 11, no. 2, pp. 135-36.

[4] D. Petherbridge, The Primacy of Drawing: Histories and Theories of Practice, Yale University Press, Connecticut, pp. 19, March 2010.

[5] A. Geim and K. Novoselov. (6 December 2010). Nobel.org, Interview with the 2010 Nobel Laureates in Physics. [Online]. Available: http://www.nobelprize.org/mediaplayer/index.php?id=1408

[6] A. Geim and K. Novoselov. (6 December 2010). Nobel.org, Interview with the 2010 Nobel Laureates in Physics. [Online]. Available: http://www.nobelprize.org/mediaplayer/index.php?id=1408

[7] R. Hare, "The Act of Sketching in learning and teaching the design of Environments: A Total Skill for Complex Expression," Electronic and Open Journal, Drawing and Visualization Research, TRACY, Loughborugh University

[8] C. Close. (2007). Painting Process/Process Painting, MoMA talk at Museum of Modern Art NYC. [Online]. Available: http://www.youtube.com/watch? $\mathrm{v}=\mathrm{Cg}$-zsxsalS8

[9] Q. Y. Xiang, 2011 drawing homework, Engineering Student at Nanyang Technological University.

[10] Q. Y. Xiang, 2011 drawing homework for A/Prof. Joan Marie Kelly, Engineering Student at Nanyang Technological University.

[11] W. I. B. Beveridge, "The art of Scientific Investigation," Norton in New York, pp. 55, 1957.

[12] W. I. B. Beveridge, "The art of Scientific Investigation," Norton in New York, pp. 55, 1957.

[13] R. M. Felder, "Learning and Teaching Styles in Engineering Education," Engineering Education, 1988, vol. 78, no. 7, pp. 674-681.

[14] J. M. Kelly, "Student \#3 Drawing titled, 'One House, One Car, One Person," Nanyang Technological University, Singapore, 2012.

[15] J. M. Kelly, "Student \#3 3 discusses her ideas for her drawing titled: 'One House, One Car, One Person,"” Nanyang Technological University, Singapore, 2012. 
[16] J. M. Kelly, Singapore Student 2011 feedback email, Singapore Student homework, Nanyang Technological University.

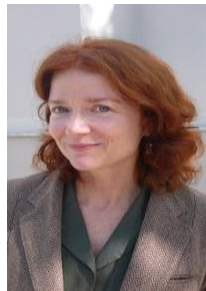

Joan Marie Kelly is an American artist based in Singapore. She completed a Masters of Fine Arts, Painting at Western Connecticut State University and Bachelor of Fine Arts at Maryland Institute College of Art. She is an Assistant Professor at Nanyang Technological University in Singapore, where she teaches fine art drawing to engineering students. Recent solo exhibitions were held in New Delhi, New York and Massachusetts. Future exhibitions include:
Beihang University Gallery in Beijing, May 2013, International Izmir Biennale, 2013. 2012 publication titled: "Zones of Contact, the Public Art of Joan Marie Kelly"

Assistant Professor Joan Marie Kelly is a member of the College Art Association, and American Association of Museums. Her artwork is collected internationally. She recently was awarded The Achievement in Figurative Painting, $1^{\text {st }}$ Prize and Honorary Ambassador at the Ecorea Jeonbuk Biennale South Korea 2012 